\title{
The Basque Bilingual Education System: A Model for a Kurdish Bilingual Education System in Turkey
}

\author{
Burhan Ozfidan \\ Zirve University, Turkey
}

\begin{abstract}
The main target of the study is to demonstrate how the Basque bilingual education system in the Basque Country of Spain works, and how it may be used as comparative analysis of a possible bilingual system for the Kurdish population in Turkey. Basque bilingual education models used where minority languages are prominent will be considered, taking into account their historical and political contexts. This study is also to discuss the benefits of Basque Country's bilingual education models in Turkey and what they can offer in regard to issues related to the lives of Kurds in the country. The overall design of this study uses a qualitative method consisting of data collection through a survey used to get a rich data set that explains the issues surrounding bilingual education in the Basque region. This survey involved 26 participants from K-12 teachers and scholars in the Basque Country. From the survey, the participants' answers were gathered and reviewed. Emergent themes in the survey were coded. Results indicate that currently, the Basque Country in Spain has a reputable ongoing bilingual education system. Over the last decade, the Basque region has established a model for bilingual education that offers multiple options for the linguistic study of the Basque language. Thus, as the Basque Region has an advanced and institutionalized bilingual education system, it is logical to study how minority language issues were addressed previously so it may inform the Kurdish situation.
\end{abstract}

Index Terms — bilingual education, Basque Country, Kurdish, Turkish

\section{INTRODUCTION}

For decades, Turkey has been a monolingual nation. The largest ethnic subgroup in Turkey is Kurds, who have been fighting for linguistic recognition for years. Ucarlar (2009) affirmed that some of the primary Kurdish concerns are language and culture. At present, the Turkish state dictates the curriculum, language of instruction, and educational goals. In some circumstances, this has left those who are not familiar with Turkish culture, outsiders in the community, without access to education, which is only offered in Turkish. In the spring of 2012, the Turkish Prime Minister, Recep Tayip Erdogan, announced that students would be able to take Kurdish language as an elective in certain schools in the eastern parts of Turkey. This eastern region is also inhabited by groups who can speak multiple Kurdish dialects and languages other than Kurdish. Therefore, Kurdish education should not be developed in single model form; rather, multiple educational models need to be developed for education in the mother tongue and be continuously revised according to the needs of the students. Thus, scholars in Turkey continue to investigate the appropriateness of other linguistic models such as bilingual education.

An important issue for Turkey is to ensure that all students are able to receive education in their native language (McCarus, 1960). Kurdish language is derived from the western Iranian branch of the Indo-European language family. According to Ethnologue Language of the World (2011), the Kurdish language has 16 million speakers in Turkey today. In addition, KONDA (2011) showed that $11.97 \%$ of the entire population of Turkey speaks Kurdish language as their first or second language. The Kurdish language has many different dialects, but these are connected through a single written language. Campbell (2000) emphasizes that there are two main dialects of Kurdish: Sorani and Kurmandji. Sorani is spoken predominantly in Iraq and Iran, while Kurmandji is spoken in Turkey and the regions directly to the east, northeast, and southeast.

Currently the Kurdish population inhabits virtually all provinces in Turkey, making up approximately $17-25 \%$ of Turkey's population; however, the majority of the Kurdish people dwell in the southeastern provinces, in the rural and highland territories close to northern Iraq, Iran, and Syria. Turkey's 95\% of the population is Sunni Muslim. Huge numbers of the Kurdish people also are Sunni Muslims. A few numbers of the Kurdish populations inhabiting in Turkey are Shi'a Muslim (Polat, 2007).

In Turkey, published material in the Kurdish language was prohibited until the 1990s. The government also placed constraints of speaking Kurdish in education and media (television and radio) in 2002. Speaking Kurdish language in private institutions is allowed but not in basic public education institutions. Furthermore, it is an ongoing debate whether or not the Kurdish language should be allowed to be used in the either public or private institution within the 
country. However, Turkey permitted private television channels to commence programs in Kurdish in 2006, which shows that the political establishment is becoming more open to the use of the Kurdish language (KONDA, 2011).

Even though there are few cultural and linguistic similarities between the Basque and the Kurdish people, what similarities there are, are of vital importance to those observing and studying the process of similar nationwide cultural conflicts and the impact they have on the people themselves as well as their language. These similarities comprise the connection of the Basque country to the Kurdish area. Both of the Kurdish and Basque people have lived in neighboring regions close to larger countries, and thus have had similar cultural experiences at the hands of those countries' military regimes and their persistence for conquest. Because of the effect of military force against both of these groups of people, both the Basque and Kurdish have had their linguistic and cultural freedom oppressed and severely restricted. This being said, there are particular differences between these two regions, from the level of prosperity between people in the Basque country and in the Kurdish territory to differences in the direction of their inner migrations (Coskun, Derince, Ucarlar, 2011).

Spanish and Basque people have been in touch in the Basque Autonomous Community (BAC) for along time and there was a long built motive of dialogue among them, even though it is quickly altering in the near future (Zuazo, 1995). In a 2008 study, Zalbide and Cenoz asserted that Basque language was used everyday in the whole informal circle of life for the population of the Basque Country in Spain. On the other hand, Spanish was the formal language, the literacy- associated powerful language, of academia and of the high-status communication complexes. Conventionally, education was mostly in Spanish, even though one of its essential factors, religious generation, was bilingual in its written system and, at least in the beginning, mainly Basque was spoken in the region. However, this dialogue has declined considerably because of many reasons for instance industrial revolution and transportation, urbanization and universal education, and non-Basque speaking immigration or language policy following a single language state. These circumstances in the Basque territory could be defined as incomplete bilingualism. Spanish has appeared in the home in most regions. Basque, however, has started to speak in schools, in the local media and in the street; nevertheless, never so far as to diminish Spanish's main role, excluding at school.

Another difference is that Spain and the Basque region have established a system regarding minority education, whereas Turkey has yet to address this issue as fully. By more fully examining the Basque system, it may help to inform developments in Turkey.

\section{LITERATURE REVIEW}

Since 1923, the Kurdish issue is still the most serious internal issue in Turkey. In a 2007 study, Polat affirmed that the Turkish republic's governmental policy in 1923 attempted to build a personal identity and sense of belonging to one nation under the appearance that Turkey was inhabited by only one nation and only one language which was Turkish. The formal language was thus deemed solely Turkish. However, the learning and speaking certain languages for instance German, French, and English were approved and encouraged within this period. Kurdish people, however, were not permitted to speak their native language in the streets, in any social areas, not even in their own homes, let alone governmental institutions, and in schools (Akreyi, 2011).

In 1923, Turkey's constitution, prohibiting Kurdish language was written into law (May, 2001). The law indicated that Kurdish had no grammatical rules and a vocabulary of approximately only 8,000 words, of which only 300 were originally Kurdish, the rest being from Turkish, Arabic, and other languages of region, that Kurdish was not an actual language, (Hassanpour, 1992).

By the 1950s, use of the Kurdish language in everyday private life was legally tolerated, however use of the language in public was still prohibited (Kendal, 1980). In the early 1960s, according to Polat (2007), Turkey accepted a new organic law in which some publications in Kurdish were permitted. However, from the 1960s to the 1990s, between the controlling government and the political Kurdish movement there was an enlarged restraint on Kurdish language and culture due to the increasingly hostile relationships. During this period of time, Turkish politics, and numerous military coups took place were ruled by the army. In the constitution of 1982, the laws prohibiting the use of Kurdish in the public territories written in 1923 were reenacted (May, 2001). Furthermore, greater militarization and political control of the Kurdish territories were extended through new assimilation programs with a general campaign to develop reading and writing abilities in Turkish with more Turkish language courses introduced in elementary school by the late 1990s (Hassanpour, 1992).

In the way of language rights, Skutnabb-Kangas and Bucak (1995) pointed out that Kurdish activists pursued firstly to remove the ban contrary to the Kurdish language to acquire tolerance rights, as had been existing throughout the Ottoman Empire before 1923. Nevertheless, afterward accomplishing tolerance rights at several times in the previous half century, Kurdish people began to pursue their language rights to facilitate language maintenance. The purpose has been primarily to succeed not only in gaining the freedom to write and speak the language, but also the right to teach Kurdish and have education in the Kurdish language.

Currently, on June 12, 2012, the Turkish government has proclaimed plans to allow schools to teach Kurdish as an elective subject. Prime Minister Recep Tayip Erdogan pointed out that 
"Kurdish language can be taken as an elective class in Turkey; it can be taught and be learned. This is a historical step. This way, our citizens with different mother tongues can develop their languages and cultures according to their needs and demand."

Lessons in the Kurdish language will be granted in schools from now on. This is a big step for bilingual education in Turkey. The government in Turkey has been taking democratic steps about Kurdish people's rights, but Turkey worries that consenting education in Kurdish might divide the country along different ethnic groups (Albayrak, 2012).

\section{Bilingual Education System in Spain: The Case of Basque Bilingualism}

The Basque Provinces are located in Northern Spain, bordering the Atlantic Ocean and France. The Basque Autonomous Community (BAC) has three regions: Bizkaia, Gipuzkoa, and Araba within Spain, and culturally including a fourth province (Nafarroa) and a small portion of France: Lapurdi, Nafarroa Beherea, and Zuberoa. As Zalbide and Cenoz (2008) pointed out, the Basque Country's population is roughly three million and almost two-thirds of the population lives in the BAC in Spain. In this area, Basque is a minority language, which has survived along with Spanish. According to the most recent sociolinguistic survey, 557,600 speakers, or $30.1 \%$ of the population are aged 16 or older (Cenoz, 2012).

\section{Basque language history}

The rapid urbanization around Spanish and Basque industrial provinces caused the Basque language to disappear entirely from the economic and public arena until the late 19th century (Lasagabaster, 2001). The Basque language was officially prohibited from education throughout the Franco's dictatorship and resistance fighters often hid in the Basque country from 1939 to 1975 . However, in the 1960s, in spite of legal structures, groups of eager teachers and parents in the BAC struggled for and achieved the re-opening of several private Basque schools. When these schools first opened they were not officially accepted; however, the government under the Franco regime was finally forced to accept the new Basque schools since they had attracted a large number of students that could not be ignored. After the Franco regime ended, a new political environment that was more inclusive to Basque and the Basque Country came out and exists to the present day.

In 1959, under Franco's dictatorship, ETA (Euskadi ta Askatasuna, in English: Basque Homeland and Freedom) a nationalist group, emerged that claimed to fight for the independence of the Basque Country. This coincides with a second wave of industrialization and immigrants from other parts of Spain. ETA is one of the oldest nationalist organizations in the world (Sánchez-Cuenca, 2008). It claimed its first victim in 1968, and it is still active at present, after having killed approximately 750 people (until the end of 2007) and wounded thousands of others.

Lasagabaster (2001) emphasizes that the overwhelming political atmosphere deriving from internal conflict, international war, and the military despotism that dominated the 20th century has hurt the conservation and development of the Basque language. While in the early 20th century, the rate of those who spoke the Basque language in the Basque province was around $83 \%$, by the end of the century this rate had decreased to $24 \%$. Haddican (2007) affirmed that the Basque Language Academy, which was activated once again in 1960, attempted to standardize the Basque language to a version named Batua. At the same time it also worked for grounding of the essential infrastructure for official Basque education to be established in later years. Additionally, Haddican also affirmed that Basque education was created non-officially, via a night school network prepared secretly in the late 1960s and early 1970 s. The education held in these secret schools, known as Ikastola, would obtain first legal and then special status in later years and would become an element of public service.

At the end of Franco's regime bilingual education models were founded beginning in 1975. Mandatory education in the BAC comprises six years of elementary education for 6 to 12-year-old children and four years of secondary school for 12 to 16-year-old children. Many students go to school from the age of two and many attend Basque day-care centers from an even earlier age (Zalbide \& Cenoz, 2008). This current system is successful in its incorporation of both mainstream Spanish language and the preservation of Basque culture.

\section{Current models $(A, B, D)$}

Zalbide \& Cenoz (2008) emphasized language instruction; both Spanish and Basque became mandatory focuses in all schools and education in the Basque language, which started officially in 1976, was established through three different models of schooling: Model A, Model B, and Model D. These three models are voluntary to students. In Model A, virtually all subjects are taught in Spanish and as a second language Basque is taught for three to five hours a week. In this model, students as a second language obtain minimal proficiency in Basque. The purpose of this model is to make stronger positive attitudes towards Basque culture, to help students understand the Basque language, and to get ready students to participate in Basque environments (Gardner, 2000). Model B is planned for Spanish native speakers who want to be bilingual in both Spanish and Basque. Basque is taught for roughly $50 \%$ of the instruction time and the other half is taught in Spanish (Arzamendi \& Genesee, 1997). The purpose of this model is to obtain appropriate capability to be fluent in Basque, to prepare students to perform further studies in Basque, and to secure a high level of comprehension (Garden, 2002). In Model D, Spanish is taught as a subject and Basque is the language of instruction for four to five hours a week. The purpose of the model is to reinforce capability in Basque, convert Basque into an instrument of communication for conversation and enrich language abilities, and teaching and to acquire a satisfactory knowledge of Spanish (Gardner, 2000). Eventually, Model D can be appeared as both a total immersion program for 
native speaker of Spanish students and first language maintenance programs for native speakers of Basque. Each of the models is available both in the private and public sectors; parents can select the model that they want for their children. In some areas of the country where there are not sufficient students interested in a particular model, Accessing to all three options is restricted (Gardner, 2000). According to statistics for the numbers from 2003 to 2006, Etxeberria (2006) pointed out the enrollment in the different linguistic models in the BAC: Model A accounts for only $8.10 \%$ of pupils, model B for $30.5 \%$ and model D for $61.4 \%$. In the 1980 s, although student registrations in model A outnumbered that for models B and D put together, model A is currently declining.

\section{Curriculum}

In a 2000 study, Gardner affirmed that the introducing Basque into teaching on an extensive official base brought with it the need to describe the curriculum, especially for Basque literature and language. Other subjects, for instance History and Geography, where a specific Basque-centered element earned to be introduced would need to be incorporated into the curriculum. Additionally, the materials essential to teach all topics in Basque were immediately required as well. The government needs to be more supportive in the incorporation of bilingual education whereas currently funds are mostly left to private means. Nevertheless, the government provides various economic funds, yet not nearly enough. Gardner also affirmed that finance mechanisms have improved with time. Ikastola schools by the end of the Franco regime were completely funded by the parents. Public schools were completely reinforced by central government (Madrid) finance. On the other hand, with parents paying various additional amounts, private schools were considerably funded and supported by central government. After Franco's death, central government to ikastola schools provided various restricted financial supports. Individuals and companies who got funding from the Basque Government produce the teaching materials. According to Gardner and Zalbide in 2005, this funding is hinged on the primary of equal opportunity so that parents who have to buy Basque materials do not have to spend more that if people bought them in Spanish.

\section{Teachers' proficiency}

Zalbide and Cenoz (2008) found that in the Basque Autonomous Community (BAC), to be hired for the teaching of Basque in the level of command of the Basque language required of a teacher is one of the chief challenges for the educational system. In order to be qualified, according to Zalbide and Cenoz, teachers have to get a diploma of proficiency. Before teachers got a job, they acquired this diploma; however, many others were already teaching through the medium of Basque and studied Spanish to be qualified. In many instances there were teachers who had native in Basque, but had only used Basque verbally since the language of instruction at that time there students was in Spanish. In these instances special courses to obtain literacy abilities and strengthen their grammar and vocabulary have been organized.

To conclude, in the Basque Country, there is a innovative legal condition, more potential learners and speakers than ever before. Gardner (2000) affirmed that the new Basque generations of native speakers are completely literate and well educated in the Basque language, an entirely new phenomenon that is giving growth to a new wave of printed materials. Gardner also pointed out that many books have been printed in the Basque language per year. Using Basque as bilingual in the church, in secondary and elementary education, and in printed materials continues to enlarge. The Basque language is being used in zones it has never been used in before: University, administration, audiovisual materials, and computer software. To sum up, the people who have predicted the near-immediate death of Basque over the last 200 years have made a blunder. The existence of Basque has now been ensured at least well into the 21 st century.

\section{METHODOLOGY}

\section{Design}

The overall design of this research project is a qualitative method consisting of data collection through survey in order to obtain a rich data set that explained the issues surrounding bilingual education in the Basque region. The researcher used the case study method of qualitative research in which a single person, event, program, institution, process, organization, phenomenon or social group is examined within a specified time frame, using a appropriate compounded knowledge collection devices (Creswell, 1994). Because this study examine the Basque bilingual program and historical backgrounds, this study is appropriate for case study of research methods. This study's research questions and surveys are useful in providing answers to 'Why?' and 'How?' questions, and in this role can be used for explanatory descriptive or exploratory research. Therefore, this study is appropriate for a Case Study of the research method's procedures.

\section{Setting and Procedures}

There were 26 participants from K-12 teachers and scholars in the Basque Country. Participants were asked to volunteer to be part of a master's thesis research study. The researcher sent the survey link to an assistant professor who in he Basque Country in Spain. He then sent out the request for voluntary participation through his network of professional and organizational contacts. He contacted the participants via email to cover the most potential participants because the recruitment material needed to be written in Basque, Spanish, and English. Participants who agreed to partake in the survey had limitless time to complete the survey. 
Cross-case theme analysis was used as an appropriate analysis technique for case study. It reassembles the data based on logical connections between categories (Creswell, 1994). The researcher developed categories for the different themes. Coding categories were a means of sorting the descriptive data so that the material represented patterns among and between the survey questions. Researcher's notes were also examined for themes in the bracketing way.

\section{FINDINGS}

This paper explains questions surrounding the bilingual education curriculum in the Basque region. This survey was taken from 26 participants, 8 males and 17 females, from K-12 teachers and scholars in the Basque Country. From the survey, the participants' answers were gathered and reviewed. Emergent themes in the survey were coded.

Theme One: Forbidden Language

Participants were asked to answer how language schooling was done before the establishment of the current system in the Basque Country. This question was answered by 11 participants, 7 K-12 teachers and 4 scholars. According to literature, the Ikastolas were privately and publicly supported schools with a special legal status. These schools do not exist as a legal entity any more and they were related to a movement supporting the Basque language. However, they have merged with state and private schools and they operate within the Federation of Ikastolas (Haddican, 2007). One participant pointed out, "during the Franco regime and resistance fighters often hid in the Basque Country. The Basque language was prohibited around the Basque Country in educational zones." According to K-12 teachers, school monolingualism in Spanish was characterized through 1935 to 1960. During this period consistently within the principles of the "Movimiento (Movement) National," i.e. Franco's doctrine, the key concern was to educate students in a uniform way. Because of the Franco regime, people were forced to speak only Spanish. One of the teachers pointed out, "we went from a dictatorship to a 'democracy', and then we had huge changes. In the past, Basque language was not allowed to be taught, and only Spanish and Spanish cultures were taught in the classroom." Participants also mentioned that in the last 30 years, the development and beginning of bilingual education in the Basque Country is relevant to the movement for schools in "Euskara, the Ikastolas."

Theme Two: Bilingualism is expanding in the Basque Country

Participants were asked to answer how the current bilingual education system works. This question was answered by 14 participants, 10 K-12 teachers and 4 scholars. According to one of the teachers' answer, "current bilingualism works perfect...because there are three different bilingual models...all three are optional...if you want to learn Spanish or Basque it is up to you, you can learn either Spanish or Basque language." Bilingualism has a legal position and many speakers are steadily increasing. According to participants, the sociolinguistic condition of Basque language is better than ever before. It has extensive societal support and more books are published in Basque than in all the precedent centuries combined. One of the scholars asserted that, "Basque language is being used in areas it has never been used in before such as in universities, in technology, computer software, churches, and official zones, among others." Participants also affirmed that the Basque bilingualism is of huge interest in the context of the European Union. Currently, it represents a dynamic, changing scenario, full of contradictions and new proposals that are hard to interpret, yet ideal for studying all the questions raised as challenges for the future.

Theme Three: Perception of the Model D

Participants were asked to answer questions about the advantages/disadvantages of bilingual models in the Basque Country. This question was answered by 14 participants, 9 K-12 teachers and 5 scholars. According to participants' answers, they are convinced of the benefits compared to their monolingual counterparts in Basque bilingualism models. One of the scholars emphasized that, "model D is the only one that is close to a balanced bilingual approach because its graduates are equally fluent in the two official languages (Basque and Spanish) around the Basque region. Student competence in both languages is quite good." According to participants, model D is the best one because the students obtain a good level of Basque language but are bilingual when they finish their studies. Model B is also good one however, one of the teachers affirmed that, "it is not as good as model D because students learn some Basque, but they can't communicate fluently so they avoid using it." Participants also pointed out Basque bilingualism promotes biculturalism, which students need to understand the value of their culture and language. Besides this, Basque bilingual models help improve students' self-esteem and the willingness not to hide their feelings about his or her culture.

As disadvantages of Basque bilingual models, participants asserted that currently model A has been used very rarely because it would mean that all learning be carried out only Spanish. One of the teacher participants pointed out, "Basque is just another school curriculum subject, and therefore, model A is now tending to disappear." According to participants, for bilingual models, there is a "lack of classrooms" that can accommodate students who require instructions in both Basque and Spanish languages. Students are expected to sit together in one class irrespective of their age and the differences in the required level of education. This brings out a big problem for teachers who have to display a certain level of comfort in handling distinct levels of education at the same time. Participants also affirmed "the lack of teachers" in schools. The teachers in school felt stressed when they needed to teach the same subject in Basque and Spanish. Therefore, participants suggest that government should provide training to teachers who teach Basque and Spanish in the same subject. The teachers, they said, should spend more time to explain things to the students and communicate with them.

Theme Four: Nondiscrimination area in the Basque Country 
Participants were asked to answer how bilingualism affects relation between different ethnic groups. This question was answered by 11 participants, 9 K-12 teachers and 2 scholars. According to most of the participants, bilingualism does not negatively affect any ethnic groups in Basque country. One of the teachers asserted that, "bilingualism does not affect any ethnic groups negatively in the Basque Country... on the contrary, I think bilingualism makes very good strong relationships between different ethnic groups (Spanish and Basque). I don't think bilingualism creates a discrimination environment." Bilingual models in Spain are a portion of the country's policies in addressing the demands and needs of ethnic population groups. According to one of the scholar's answers, "the bilingual education system does not separate any ethnic groups such as Spanish and Basque people in Basque Country." Participants also affirmed that they all live as brothers in the same country.

Theme Five: Language preserves culture

Participants were asked to answer if bilingualism helps preserve Basque linguistic and cultural heritage in the Basque Country. This question was answered by 12 participants. All participants' answers were quite affirmative. According to one of the participant's answers, "language, religion, and customs are usually described in ethnic identification." Basque language is "the cultural symbol of Basque identity," and all history and cultural customs of the Basque groups have been recorded in their language. Another participant pointed out, "If anyone's language disappeared, this mean this person's cultural heritages are going to be disappeared...if you don't use your mother tongue it will be getting rusty." Without the language, the history and cultural success could not be inherited by the new generation. According to participants, the right to preserve their own language and traditional culture is one of the basic human rights supported by international society today. Participants also affirmed that if bilingualism did not emerge in Basque Country, Basque language might vanish, as its functions as a communication tool decline with modernization and globalization. The disappearance of any language is predictable, though many people cannot emotionally accept this reality. If a small group insists on preserving its own language but rejects learning other useful languages, the group's limited capacity to learn and communicate will place them at a disadvantage in social and international competition, and obstruct their future development opportunities.

Additional results not clearly fitting a theme:

Participants were asked to give their advice on how to establish a bilingual education system. This question was answered by 11 participants, 8 K-12 teachers and 3 scholars. According to participants' answers, the first and biggest difficulty was the "lack of qualified teachers." One of the scholars highlighted that, "bilingual teacher-training departments should be set up at universities, particularly in minority areas." According to scholars, teachers who are already working in schools attended by minority students should be given in-service training on teaching students whose mother language differs from the language of instruction. Secondly, participants pointed out there should be an extensive variety of materials to select from in elementary and secondary school. A teacher participant asserted that "materials for primary and secondary school should be increased and accessible." Participants, teachers, also asserted the minister of education in the country should establish numerous programs to incentivize the production and creation of different language material. The third important thing is governmental support. One of the scholars affirmed that "government should cover the publication of textbooks." Participants also informed that government's support is fundamental and vital; therefore, the government should fund audio-visual resources, software and the formation of working groups dedicated to the design of new materials. Lastly, participants emphasized that bilingualism should be used in many areas such as universities, administrations, computer software, audiovisual materials and media, among others.

\section{DiSCUSSION AND RECOMMENDATIONS}

There is a parallel situation of the in regard to Kurdish language education in Turkey to Basque language in the Basque region of Spain. The Basque model in Spain, where minority languages are used in education, are discussed, taking into consideration their political and historical circumstances. The purpose of these discussions was to establish a sense of the shortcomings and benefits of particular bilingual models and their relevance to the Kurdish situation in Turkey. An effective and enhancing education should require flexible school systems that can respond rapidly and efficiently to different regions' various needs. "The implementation of a bilingual educational policy that accepts the use of the mother tongue in education necessitates decentralization of the administrative structure" (Coskun, Derince, Ucarlar, 2011, p.127). Essentially, this can be seen in cited examples of Spain's incorporation of the Basque language. Adapting a model in Turkey similar to Basque models would allow students to recognize and display a more positive attitude towards school. Implementing a bilingual model would also help students' self-confidence and therefore affect their school achievement. Additionally, students who acquire such an effective and enhancing education will be able to improve communication with other cultures and languages and will feed on the intercultural dialogue essential for societal peace. The benefits brought about by these measures can be seen in the Basque language example. Implementation of Basque bilingual education models should positively be taken into consideration during the development of policies in Turkey regarding the use of the mother tongue as a bilingual education.

Kurdish-Turkish bilingual educational models should be developed for the education of Kurdish and Turkish students. In parallel to this development, essential work should be carried out for the implementation of other educational measures like the measures currently being employed by Basque programs. It must not be forgotten that it is essential to 
continuously revise bilingual education models in line with changing needs and conditions. In respond properly to these issues, Turkey needs to develop its own model. During the development of this model, the students', teachers' and parents' needs like those of citizens of the Basque Country should be taken into consideration; experiences of countries that have cooperate with and are continue to handle such issues and academic and pedagogical studies conducted on these experiences can be beneficial to Turkish education. All in all, I hope that monitoring Basque Country's efficient bilingual models will provide inspirations for the development of a Turkish model for use in Kurdish bilingual education.

The problems inherent in Basque bilingual models should be studied while establishing policies for education in the mother language in Turkey. The conclusion that only education in the mother tongue can be applied equally all over the country or all over the relevant area may cause new results to be drawn easily from the Basque education. Kurdish people are spread all over Turkey and not simply located in the Eastern Provinces. Likewise, the Kurdish region is also inhabited by groups who can speak languages other than Kurdish and, amongst the speakers of Kurdish, a variety of dialects. Therefore, it should not be forgotten that education in Kurdish should not be developed in the form of a single static model. Educational models need to be developed for education in the mother tongue and be continuously revised according to the needs of the students.

\section{Recommended Model for Bilingual Education Implementation in Turkey}

From the findings of this study, it is possible to put forth a number of linguistic, social and cultural recommendations concerning the educational policy and practices to be followed in schooling of Kurdish students who speak little or no Turkish when they start school.

In a current study, Coskun, Derince, and Ucarlar (2011) found that Kurdish language should be used in Turkish education and bilingual educational models should be developed and implemented. A permanent way to get rid of the discrimination experienced by Kurdish students would be to use their native language in the education system. On the other hand, the assimilation of the Kurdish language into Turkish education is undoubtedly an extremely complex and complicated problem. The design and usage of school models aspiring to be a balanced bilingualism in Kurdish and Turkish should play a vital role in lifting the damages and disadvantages of Kurdish students. In addition, bilingualism will aid the literacy in the two languages and support the education of Kurdish children. The development of bilingual educational models can be gleaned from bilingual educational models in different countries such as bilingual education models in Spain, the case of Basque Bilingualism. Nevertheless, taking an educational model that has been successful in another country and implementing it with new languages will probably produce weak results resembling submersion models. To develop strong models to be used in the education of Kurdish children, the current issues, detailed observations, and various circumstances should be taken into consideration. However, in order to develop models that will be implemented in the future, it is essential to begin building the necessary infrastructure right away.

According to DISA's (Diyarbakir Institute for Political and Social Research) report in 2011, bilingual educational models should cover all school levels because learning and culture are lifelong experiences; in order to be proficient in both, they must be a consistent presence in life. Conditions, needs, and accessible objectives should be identified, and the models to be developed should not be restricted to the first years when students gain the skills of reading and writing. Besides, students should involve long-term programs covering all stages of education, from primary school to higher education. An alternative model would not play a role or have any influence on the secondary and higher education. Also, using a single language educational model in either language that students would not be accountable for in countrywide centralized examinations such as OSS (university entrance examination) will prevent students from learning one of the languages and the model from being completely successful.

\section{Teacher Preparation}

Cummins (2000) affirmed that training bilingual teacher departments should be a main focus. The essential infrastructure should be built up and relevant departments should be opened in educational faculties for the training of teachers who will make possible the implementation of Kurdish-Turkish bilingual education. Teachers who are already working in schools attended generally by Kurdish students should be given in-service training on teaching students whose first language (L1) differs from the language of instruction. Training Kurdish teachers on bilingual education is also necessary. Kurdish teachers who sometimes prefer speaking Kurdish with their Kurdish students in an attempt to allay their disadvantages should be given seminars on bilingual educational methods, strategies, and textbooks.

Coskun, Derince, and Ucarlar (2011) pointed out that teachers who work in the Kurdish region should be encouraged to learn Kurdish. The significance of learning Kurdish for teachers who will teach in the Kurdish region is that they can be taught the Kurdish language, culture, and literature. It is necessary to provide free Kurdish language courses specifically for these teachers. From this point of view, teachers who learn Kurdish may be able to build more productive, genuine, and constructive relationships with both Kurdish students and their parents. This will encourage an identity negotiation and may positively contribute to Kurdish students' school achievement and help reduce the existing social and economic inequality and discrimination. Free Kurdish language literacy courses should also be provided for students who speak Kurdish but do not know how to write and read in Kurdish so as to re-establish certain attitudes to language and their self-efficacy. Seeing students' native language in written texts and being able to make use of these texts may have a corrective and constructive process on their relationship with the school and with their native tongue. Literacy courses will provide the ground for the implementation of bilingual educational programs in Turkey. 


\section{Availability of Resources to Teach}

A concern that Anderson (2009) voices in his study is the availability of resources to teach in Kurdish. Manufacturing new teaching materials - such as textbooks -- can be very expensive. However, Anderson emphasized that given the considerable size of the population of Kurdish people, the relative cost of publication of books would be reduced considering the high number of people. Because the standards for education are already in place and textbooks already exist, the challenge will be in producing logical and authentic translations of these resources into another language. There can be some cost associated with this process, but it should not be high-priced. The government should provide some economic support.

Bilingual teacher-training departments should be set up at universities, particularly in the eastern part of Turkey. Teacher training should be provided for the transformation of coercive teacher-student relations (Cummins, 2000). Kurdish-Turkish education models should be developed very well for the education of Kurdish students.

It is also necessary that parents should be considered part of the bilingual educational process. Providing free Kurdish literacy courses for Kurdish parents, whether or not they are already able to read and write Turkish language, would be a positive first step in this direction. The steps would provide parents the skills and knowledge to become empowered and assist in their children's education. Such courses would also be vital in that they would provide access to broader resources.

Sheyholislami (2008) pointed out that Kurdish television programs should be created to help Kurdish students' develop language skills. Considering the significance of first language proficiency in accomplishing better social and academic development, television programs aiming to develop children's mother tongue should be created by the government or private television channels broadcasting in Kurdish. Resources should be provided for the preparation of programs of this kind. In this same mindset, the prohibition on children's programming for radio and television broadcasting in Kurdish should be abolished (DISA, 2011).

\section{CONCLUSION}

From the findings, the researcher has learned that the development of a strong language policy to protect and promote the use of Basque in education and in the BAC in general has resulted in the spread of the use of Basque at schools and universities. The use of a minority language as the language of instruction and in some instances as the language of research has had an affirmative impact on the status of the language. At the same time, the use of a minority language for functions that have traditionally been implemented by the majority language faces many challenges that have been explained in this paper. These challenges change over time because bilingual or multilingual contexts are dynamic and affected by the development of languages in society. When Basque was starting to be used in higher education 30 years ago, one of the main challenges was the standardization of the language and the availability of teaching materials. Now many textbooks and other publications including on-line resources are available. The situation has improved enormously even though it cannot be compared with the availability of materials in the case of majority languages.

Findings indicate that the fundamental issue is that although measures have been taken so as to help its use in the technological and scientific world (which affects a small number of users), language planners have not taken measures to stimulate its social use, which is what actually has a more direct influence on many Basque speakers. The opportunities to use the Basque language in everyday activities varies significantly from one place to another because of the massive of existing sociolinguistic diversity in the BAC. Many Spanish and French speakers in the past and a few still today have usually regarded Basque as a rural language, suitable perhaps for rural and domestic purposes, but not for the contemporary world, technology or university.

The data analysis in the Basque Autonomous Community leads us to the consequence that the bilingual subjects enjoy certain cognitive advantages compared to their monolingual equivalents. Students should be provided with the linguistic tools that will allow them to take part in a successful learning of the minority language and to socialize in a more integrated way in the community. The outcome of the data also coincide in a consequence: since model D's students are approximately equally fluent in the two official languages in the BAC and their competence in both languages is well developed, model D is the only one which is close to balanced bilingualism. Similarly, Model A needs to be reviewed, else, the social fracture between Spanish and Basque speakers (with different attitudes and values) might be aggravated (Etxeberria, 1999).

Finally, in the case of the BAC, the researcher believes that the outcomes of this research should be made known to society in the aggregate in a much greater way than has been done as yet, so that parents select the sort of education that they ponder most satisfactory or enough for their children. It has to be said that where general agreement exists is in the fact that research into the cognitive development of bilingual subjects in bilingual educational setting is a fascinating field, and that there is still much to be covered.

Researcher can conclude that the Basque language is a prestigious language and gaining in strength, with strong social and institutional support. Nevertheless, its position in comparison with Spanish, in the way of many speakers and the development of communications media, make it a feeble minority language. Therefore, Basque is 'strong' in terms of prestige while being 'feeble' in comparison with Spanish. 


\section{REFERENCES}

[1] Anderson, C. (2009). Kurds in Turkey: Building reconciliation and local administrations. The Beyond Intractability Project, The Conflict Information Consortium, University of Colorado.

[2] Arzamendi, J. and Genesee, F. (1997). Reflections on immersion education in the Basque country. In K. Johnson and M. Swain (eds) Immersion Education: International Perspectives (pp. 151-166). Cambridge: Cambridge University Press.

[3] Akreyi, M. (2011). 19th Century mentality in 21st century: Kurdish language still banned in Turkey. Retrieved on June 12, 2012, from http://kurdishrights.org/2011/03/12/19th-century-mentality-in-21st-century-kurdish-language-still-banned-inturkey/.

[4] Aldeniz, E. (2009). What is Kemalism? Retrieved in June 2012 from http://www.erkutaldeniz.com/what-is-kemalism/.

[5] Albayrak, A. (2012). Turkey to allow Kurdish elective classes. Retrieved on June 12,2012 from http://blogs.wsj.com/emergingeurope/2012/06/12/turkey-to-allow-kurdish-elective-classes/.

[6] Campbell, G. L. (2000). Compendium of the World's Languages: Abaza to Kurdish. New York, NY: Taylor \& Francis Group Press.

[7] Cenoz, J. (2012). Bilingual Educational Policy in Higher Education in the Basque Country. Language, Culture and Curriculum, 25(1), 41-55.

[8] Coskun, V. Derince, M.S. Ucarlar, N. (2011). Scar of Tongue: Consequences of The Ban on The Use of Mother Tongue in Education and Experiences of Kurdish Students in Turkey. Diyarbakir Institute for Political and Social Research.

[9] Creswell, J. W. (1994). Research designs: Qualitative and quantitative approaches. Thousand Oaks, CA: Sage.

[10] Cummins, J. (2000). Language, Power and Pedagogy: Bilingual Children in the Crossfire, Clevedon, Multilingual Matters.

[11] Diyarbakir Institute for Political and Social Research, (DISA) (2011). Dil Egitimi Modelleri ve Ülke Örnekleri.

[12] Etxeberria, F. (1999). Bilingüismo y educación en el país del Euskera. Donostia: Erein.

[13] Etxeberria, F.S. (2006). Attitudes towards Language Learning in Different Linguistic Models of the Basque Autonomous Community. Garcia, O., Skutnabb-Kangas, T., and Torres-Guzman, E. (Eds) Imagining Multilingual School: Language in Education and Glocalization (pp. 111-133). England: Multilingual Matters.

[14] Gardner, N. (2000). Basque in Education in the Basque Autonomous Community. Vitoria-Gasteiz: Basque Government. On WWW at http: //www_.hezkuntza.ejgv.euskadi.net/r43 573/eu/contenidos/informacion/dia6/en_2027/adjuntos/Basque_in_ Education_i.pdf. Accessed 6.21.12.

[15] Gardner, N. and Zalbide, M. (2005). Basque acquisition planning. International Journal of the Sociology of Language 174, 5572.

[16] Kendal, N. (1980). The Kurds under the Ottoman Empire. In G. Chaliand (Ed.), People without a country: The Kurds and Kurdistan. London: Zed Books Ltd.

[17] KONDA. (2011). Kürt Meselesi'nde Alg1 ve Beklentiler (Perceptions and Expectations in the Kurdish Question). İstanbul, Turkey: İletişim Yayınları.

[18] Lasagabaster, D. (2001). Bilingualism, Immersion Programmes and Language Learning in the Basque Country. Journal of Multilingual and Multicultural Development, 22(5), 401-25.

[19] Haddican, B. (2007). "Suburbanization and Language Change in Basque," Language in Society 36: 677-706.

[20] Hassanpour, A. (1992). Nationalism and language in Kurdistan, 1918-1985. San Francisco: Mellen Research University Press.

[21] May, S. (2001). Language and minority rights: Ethnicity, nationalism, and the politics of language. New York: Longman.

[22] McCarus. R., E. (1960). Kurdish Language Studies. Middle East Journal, 14(3), 325-333.

[23] Sánchez-Cuenca, I. (2008). The persistence of nationalist terrorism: the case of ETA. Kledja Mulaj (ed) Violent Non-State Actors in Contemporary, Juan March Institute.

[24] Skutnabb-Kangas, T., and Bucak, S. (1994). Killing a mother tongue: How the Kurds are deprived of linguistic human rights. In T. Skutnabb-Kangas and R. Phillipson (Ed.), Linguistic human rights: Overcoming linguistic discrimination. Berlin: Mouton de Gruyter.

[25] Sheyholislami, J. (2008). Identity, Discourse, and the Media: The Case of the Kurds. School of Journalism and Communication, Faculty of Public Affairs, Carleton University, Ottawa, Ontario, Canada.

[26] Polat, N. (2007). Socio-psychological factors in the attainment of L2 native-like accent of Kurdish origin young people learning Turkish in Turkey. Dissertation, The University of Texas at Austin.

[27] Ucarlar, N. (2009). Between Majority Power and Minority Resistance: Kurdish Linguistic Rights in Turkey. Printed by MediaTryck, Lund University, Lund, Sweden.

[28] Zalbide, M., \& Cenoz, J. (2008). Bilingual Education in the Basque Autonomous Community: Achievements and Challenges. Language, Culture \& Curriculum, 21(1), 5-20. doi:10.2167/lcc339.0.

[29] Zuazo, K. (1995). The Basque Country and the Basque language: An overview of the external history of the Basque language. I $\mathrm{n}$ J.I. Hualde, J.Lakarra and R .L. T rask (eds) Towards a History of the Basque Language (pp. 5-30). Philadelphia: John Benjamins.

Burhan Ozfidan is currently a doctoral student in Curriculum and Instruction department at Ohio University in the United States. He received his BA with distinction in 2011 specializing in Teaching English Overseas. In 2011, he began graduate studies at the University of Nevada, Reno (UNR), where he has completed a Master of Arts in Secondary Education and Teaching specializing in Multicultural Education. His areas of expertise and academic interests are multicultural / intercultural and bilingual education curriculum including: immigration, cultural integration and assimilation of Turkish immigrants in the E.U. and the U.S.; international education, diversity; ethnic identity; second language acquisition. 